\title{
2006-643: THE EFFECTIVENESS OF ONLINE LEARNING OBJECTS IN HELPING STUDENTS MASTER REQUIRED COURSE COMPETENCIES IN MECHANICAL ENGINEERING
}

\section{Edward Perry, University of Memphis}

Edward H. Perry - is a Professor of Mechanical Engineering at The University of Memphis, where he has served on the faculty since 1970 . He received his university's Distinguished Teaching Award in 1977 and again in 2000. He also received the Herff College of Engineering's Outstanding Teaching Award in 1999. He is currently Co-Editor of the MERLOT Engineering Editorial Board and Co-Editor of the MERLOT Journal of Online Learning and Teaching. He received his B.S. (1966), M.S. (1967) and Ph.D. (1970) in Mechanical Engineering from the California Institute of Technology.

\section{Jeffrey Marchetta, University of Memphis}

JEFFREY G. MARCHETTA - joined the faculty of The University of Memphis in 2002. As a member of the AIAA, he received the Abe Zarem Award for Distinguished Achievement in 2000. His research interests include the modeling of flows with free surfaces, verification and validation of computational simulations, magnetic fluid management in reduced gravity, and particle image velocimetry. Dr. Marchetta received a B.S.M.E. degree (1997), an M.S.M.E. (1999), and a Ph.D. from The University of Memphis (2002). 


\title{
The Effectiveness of Online Learning Objects in Helping Students Master Required Course Competencies in Mechanical Engineering
}

\begin{abstract}
A study was undertaken to determine the effectiveness of using online learning objects to help students master the skills needed to satisfy required course competencies in two basic undergraduate mechanical engineering courses. Each course in the department has a defined set of required competencies that each student must satisfy in order to receive a passing grade in the course. Multiple opportunities are provided for satisfying each course competency during the semester, including the final examination.

Two introductory mechanical engineering courses, dynamics and fluid mechanics, were selected for this study. After introducing the concept underlying the given competency in class, students were assigned a homework set that required the use of an online learning object related to the competency. Mastery of the competency was tested using a pop quiz during the next class meeting and multiple-choice problems on the final examination.

The performance of students who had used the online learning object was compared to that of students in another semester who had covered the same material and had been assigned similar homework in the traditional manner of chalkboard and written assignments. Differences in the performances of the two groups will be discussed along with a learning style assessment conducted for the students in both classes.
\end{abstract}

\section{Introduction}

Several years ago our department established a set of 4-5 "competencies" for each required course in the mechanical engineering curriculum ${ }^{1-2}$. In order to pass the course, each student must successfully demonstrate that he/she has mastered each of the competencies. Various ways are used to test the competency skill, but most often "pop quizzes" are used. Students typically must get the answer to the short-answer pop quiz problem completely correct in order to satisfy the particular competency. Multiple opportunities are provided for satisfying each course competency during the semester, including the final examination.

A study was undertaken in two undergraduate mechanical engineering courses to determine if the use of online learning objects, such as those in the MERLOT collection ${ }^{3-4}$, would help students master the required course competencies. The performance of students who had used the online learning object was compared to that of students in another semester who had covered the 
same material and had been assigned similar homework in the traditional manner of chalkboard and written assignments.

\section{Learning Styles}

It has been well established in the literature ${ }^{5-7}$ that engineering students are typically visual rather than verbal learners. Nonetheless, we engineering instructors still rely heavily on the traditional lecture to teach our students. Granted that these lectures are often accompanied by sketches on the chalkboard or pictures projected onto a screen, but the primary instructional tool is still verbal in nature. All too often our instructional approach is still "instructor-centered" rather than "student-centered."

Accompanying the dramatic rise in the use of the internet in the past ten years has been the development and collection of online learning materials. A learning object is any entity, be it digital or non-digital that may be used for education and/or training ${ }^{8}$. With regard to online learning, these objects can be comprised of Web pages, portable documents, databases, animations, applets, and movies. Online learning objects are increasingly being used to supplement traditional lectures and are becoming an important foundation to the delivery of online courses. Cost-effective and efficient delivery of online learning tools has become a focus in recent years. Several organizations, activities, and consortia, such as Ariadne ${ }^{9}$, MERLOT ${ }^{10}$, $\mathrm{LRX}^{11}$, SoURCE ${ }^{12}$, and Universitas $21^{13}$, have emerged as leaders of this effort by developing libraries and databases of reusable online learning objects. Activities within these organizations include elements which emphasize design, development, and delivery ${ }^{14}$. MERLOT, the Multimedia Educational Resource for Learning and Online Teaching, for example is a "referatory" of online materials, meaning that it contains links to the materials and not the materials themselves. It currently contains links to over 12,000 learning objects, including over 400 in engineering alone. In addition, MERLOT provides user comments and peer reviews of many of the learning objects in its collection, with new comments and reviews appearing constantly.

The Index of Learning Styles (ILS) tool developed by Soloman and Felder ${ }^{15}$ was used to assess the learning styles of students in the classes involved in the study. This self-administered online tool poses 40 conjectures to the student. Upon completion of the instrument the student's learning style is characterized and reported to the student in terms of each of the following learning style pairs:

- Active vs Reflective Learning Style

- Sensing vs Intuitive Learning Style

- Visual vs Verbal Learning Style

- Sequential vs Global Learning Style

In our case we were most interested in the Visual vs Verbal learning style. 


\section{Methodology}

Two introductory undergraduate mechanical engineering courses, dynamics and fluid mechanics, were selected for this study. The courses were taught by different instructors, both of whom had taught the courses a number of times in the past. In each course students were made aware during the first class meeting of the course competencies and the fact that all competencies had to be satisfied in order to complete the course successfully.

Early in the semester each student was asked to self-administer the online Index of Learning Styles discussed above and to turn in the results of the assessment.

Material related to the concept underlying each competency was first presented in class in the traditional manner. This presentation typically included the concept itself (e.g., Newton's Second Law), the pertinent mathematical representation of the concept, and an example problem or two. Students were then assigned a homework set that required the use of an online learning object related to the particular competency. Students were surveyed in class immediately afterwards to ascertain their attitude toward the online learning object used. A pop quiz was given during the next class meeting related to the concept and similar to the way the concept had been used in the online learning object. Finally, understanding of each competency was tested again on the final examination in the course via multiple-choice problems related again to both the concept and the online learning object.

The performance of students who had used the online learning object was compared to that of students in another semester who had covered the same material and had been assigned similar homework in the traditional manner of chalkboard and written assignments.

The learning objects selected were:

- Dynamics: Mass on Incline with Friction (http://hyperphysics.phy-astr.gsu.edu/hbase/hframe.html)

- Fluid Mechanics: Frictional Losses through a Pipe (http://www.freecalc.com/fricfram.htm).

\section{Assessment}

Results of the Index of Learning Styles assessment are given in Table 1 for both courses in the study. A score of -11 indicates a strong dependence on the first of the two learning styles in each pair, while a score of +11 indicates a strong dependence on the second style. Obviously a score of zero would indicate the student is equally dependent on both learning styles in the pair.

Clearly, the students involved in our study are strongly visual learners who remember best what they see rather than what they hear or read. In addition, they are sensing learners who tend to like learning facts rather than intuitive learners who like discovering possibilities and relationships. 


\begin{tabular}{|c|c|c|c|}
\hline Learning Style Pair & $\begin{array}{c}\text { Dynamics } \\
\text { Study Group } \\
(\text { mean } \pm \text { SD })\end{array}$ & $\begin{array}{c}\text { Dynamics } \\
\text { Control Group } \\
(\text { mean } \pm \text { SD }) \\
\end{array}$ & $\begin{array}{c}\text { Fluid Mechanics } \\
\text { Study Group } \\
(\text { mean } \pm \text { SD })\end{array}$ \\
\hline $\begin{array}{l}\text { ACTIVE/REFLECTIVE } \\
\text { Active }=-11 \quad \text { Reflective }=+11\end{array}$ & $-1.2 \pm 5.7$ & $-2.0 \pm 5.8$ & $-1.1 \pm 4.8$ \\
\hline $\begin{array}{l}\text { SENSING/INTUITIVE } \\
\text { Sensing }=-11 \quad \text { Intuitive }=+11\end{array}$ & $-4.5 \pm 4.7$ & $-3.3 \pm 5.3$ & $-3.5 \pm 5.6$ \\
\hline $\begin{array}{l}\text { VISUAL/VERBAL } \\
\text { Visual }=-11 \quad \text { Verbal }=+11\end{array}$ & $-6.2 \pm 4.0$ & $-8.5 \pm 2.3$ & $-6.4 \pm 3.3$ \\
\hline $\begin{array}{l}\text { SEQUENTIAL/GLOBAL } \\
\text { Sequential }=-11 \quad \text { Global }=+11\end{array}$ & $-2.7 \pm 4.3$ & $-2.3 \pm 5.3$ & $-1.4 \pm 4.3$ \\
\hline
\end{tabular}

Table 1. Results of the Index of Learning Styles Assessment.

While ILS data were not available for the Fluid Mechanics Control Group, the data in Table 1 show little differences in the learning styles of the three groups for which ILS data were available.

Following the homework assignment that required use of the online learning object, the students were surveyed to ascertain their feelings toward the use of the online material. The survey contained the following conjectures, and students were asked to respond on a 5-point Likert scale that ranged from 1 (Strongly disagree) to 5 (strongly agree). Results of the surveys in the two courses are shown in Figs. 1 and 2 below. From the surveys it is immediately apparent that the majority ( $72 \%$ ) of the students felt online learning objects were beneficial to their understanding of the concept being addressed.

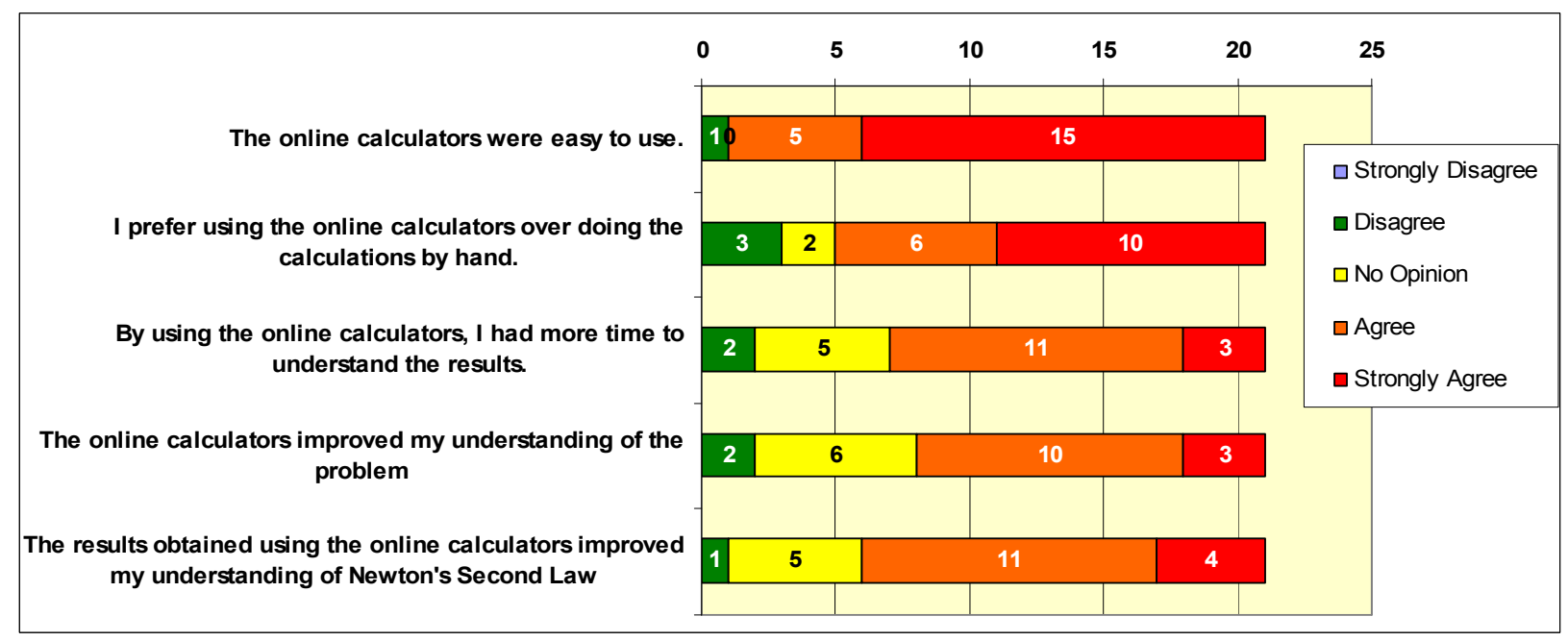


Fig. 1. Student Survey Results for the Dynamics Course

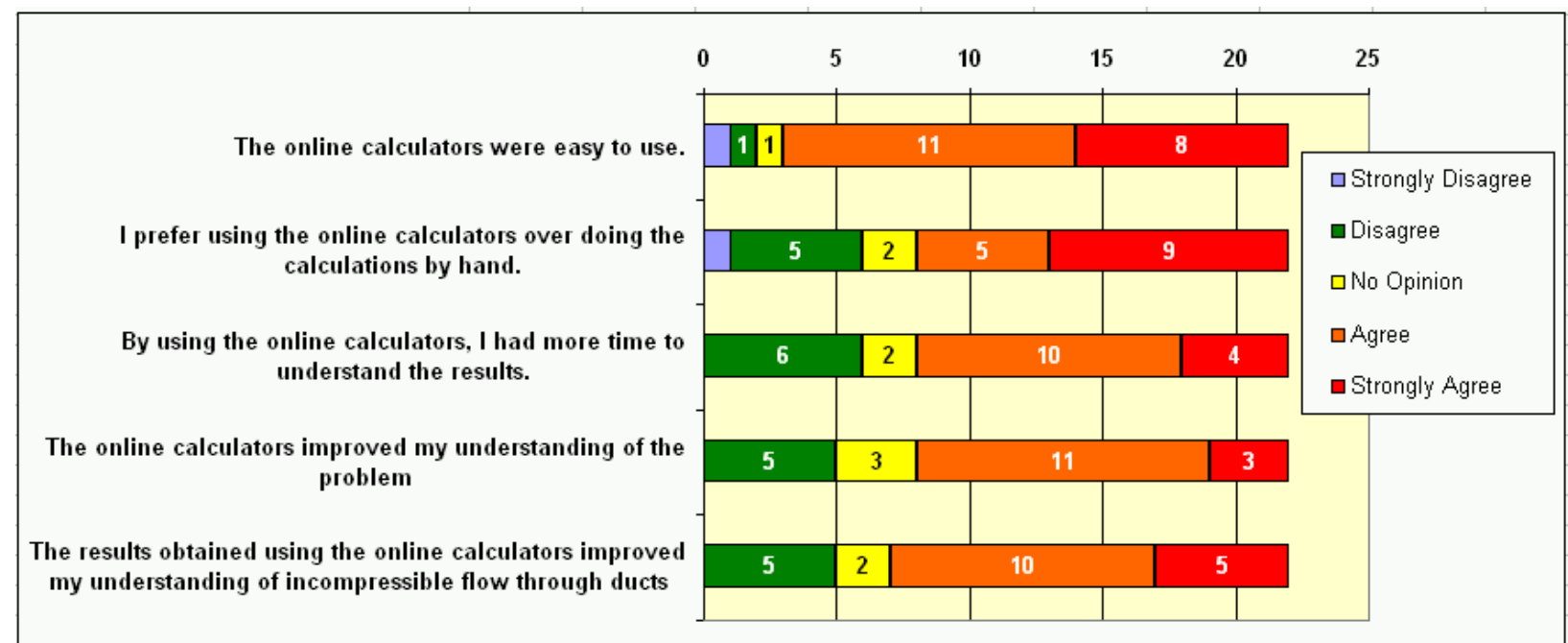

Fig. 2. Student Survey Results for the Fluid Mechanics Course

Pop quizzes were given in each of the classes to determine the students' mastery of the competency addressed by the online learning object. The results were compared to the success rates for the same quiz administered to a class taught earlier (Control Group) using only traditional chalkboard instruction techniques. Results are shown in Table 2. Also shown in the table are the incoming grade-point-averages of the respective classes. From the latter date we see that the study groups and the control groups were closely matched insofar as demonstrated ability.

\begin{tabular}{|l|c|c|}
\hline & Dynamics & Fluid Mechanics \\
\hline Study Group GPA & $2.86 \pm 0.42$ & 2.81 \\
\hline Study Group Success Rate & $4 / 20(20 \%)$ & $26 / 29(90 \%)$ \\
\hline Control Group GPA & $2.91 \pm 0.65$ & 2.86 \\
\hline Control Group Success Rate & $4 / 11(36 \%)$ & $27 / 27(100 \%)$ \\
\hline
\end{tabular}

Table 2. Success Rates on Pop Quizzes Related to Competency

In addition to the Pop Quizzes, the final exam in each course also addressed the competencies. The results for the final exams are shown in Table 3 below.

\begin{tabular}{|l|c|c|}
\hline & Dynamics & Fluid Mechanics \\
\hline Study Group Success Rate & $11 / 23(48 \%)$ & $14 / 27(52 \%)$ \\
\hline Control Group Success Rate & $6 / 10(60 \%)$ & $14 / 20(70 \%)$ \\
\hline
\end{tabular}

Table 3. Success Rates on Final Exam Problem Related to Competency 


\section{Conclusions}

It appears that while students perceive that online learning objects improve their understanding of some fundamental concepts in both dynamics and fluid mechanics, their perceptions were borne out in neither their pop quiz nor their exam performances in this study. However, because the study involved only one section of each course in a given semester, additional data must be collected and analyzed in future semesters before a final conclusion can be drawn. Such continuation studies are currently underway.

\section{References}

1. Hochstein, J.H., and Perry, E.H. : Direct Competency Testing - Is It For You? Proceedings of the 1999 American Society for Engineering Education Annual Conference and Exposition, Charlotte, N.C., 1999.

2. Marchetta, J.G., Hochstein, J.I., Tan, T.E. "The Impact of Direct Competency Testing (DCT)," Proceedings of the 2004 American Society of Mechanical Engineers International Mechanical Engineering Congress and Exposition, Anaheim, CA, November 2004.

3. Perry, E. H., Tront, J.G., Mensah, P., Rassai, R.: Use of Online Learning Objects in Engineering Curricula. Presented at the MERLOT International Conference, Costa Mesa, CA, August 2004.

4. Schroeder, B., Melder, T., and Perry, E. : Using MERLOT in Teaching Math, Physics and Engineering. . Presented at the MERLOT International Conference, Nashville, TN, July 2005.

5.Felder, R.M. \& Silverman, L.K., Learning and Teaching Styles in Engineering Education, Journal of Engineering Education, Vol. 78, No. 7, pp. 674-681, (1988).

6. Felder, R. M., Matters of Style, AEEE Prism, December Issue, pp. 18-23, (1996)

7. Zwyno, M.S. A Contribution to Score meaning for Felder-Solomon Index of Learning Styles. Proceedings of the 2003 American Society for Engineering Education Annual Conference and Exposition. ASEE 2003-454, Nashville, TN, June 2003.

8. IEEE Learning Technology Standards Committee Draft standard for learning object metadata. Piscataway, NJ: IEEE Standards Department, (2001).

9. Ariadne. [Online]. Available: http://ariadne.unil.ch/ (2006)

10. MERLOT. [Online]. Available: http://taste.merlot.org/ (2006).

11. LRX. [Online]. Available: http://www.lrx.com.au/ (2006). 
12. SoURCE. [Online]. Available: http://www.source.ac.uk/ (2006).

13. Universitas 21. [Online]. Available: http://www.universitas.edu.au (2006).

14. Oliver, R. (2001). Seeking best practice in online learning: Flexible Learning Toolboxes in the Australian VET sector. Australian Journal of Educational Technology, 17(2), 204-222.

15. Felder, R.M. \& Soloman, B.A., Index of Learning Styles Questionnaire, North Carolina State University, (2001). http://www2.ncsu.edu/unity/lockers/users/f/felder/public/ILSdir/ILS-a.htm 